\title{
ANAESTHETIC MANAGEMENT OF PARAGANGLIOMA EXCISION: A CASE REPORT
}

Pradeep M.S' ${ }^{1}$ Lakshmish Yadav Y.S 2

\section{HOW TO CITE THIS ARTICLE:}

Pradeep M. S, Lakshmish Yadav Y. S. "Anaesthetic management of paraganglioma excision: a case report". Journal of Evolution of Medical and Dental Sciences 2013; Vol2, Issue 30, July 29; Page: 5659-5662.

\begin{abstract}
Catecholamine-producing tumors are rare and may arise in the adrenal medulla (pheochromocytomas) or in extra adrenal chromaffin cells (secreting paragangliomas). Their prevalence is about $0.1 \%$ in patients with hypertension. These tumors may be sporadic or part of any of several genetic diseases: familial pheochromocytoma-paraganglioma syndromes, multiple endocrine neoplasia type 2, neurofibromatosis 1 and von Hippel-Lindau disease. The most specific and sensitive diagnostic test for the tumor is the determination of plasma or urinary metanephrine. The tumor can be located by computed tomography, magnetic resonance imaging and metaiodobenzylguanidine scintigraphy. Treatment requires resection of the tumor, generally by laparoscopic or open surgery. However, resection of these tumors can be life threatening. We present a case of functional extra-adrenal sympathetic paraganglioma excision performed using general anaesthesia with optimal hemodynamic management during the perioperative period. CONCLUSION: Functional Paragangliomas are rare tumors which are often undetected. All hypertensives, especially young should be always screened for this condition. Proper preparation of the case is required and the team should always be on high alert for the various haemodynamic challenges that can come across while managing this case.
\end{abstract}

KEYWORDS: paraganglioma, pheochromoytoma, invasive haemodynamic monitoring, labetalol, magnesium sulphate.

INTRODUCTION: Paragangliomas of the retroperitoneum are neuroendocrine tumors arising from the sympathoadrenal paraganglial autonomic nervous system. Most of the tumors arise in the adrenal medulla as pheochromocytoma, also known as intra-adrenal paraganglioma, while the remaining arise in aortic-sympathetic extra-adrenal paraganglia along the paravertebral axis as extra-adrenal sympathetic paragangliomas. Paragangliomas account for 15 to 20 percent of pheochromocytomas and have a high incidence of malignancy (13 percent to 26 percent) [1-5]. Their excision is considered extremely difficult due to their high vascularity and adherence to multiple adjacent structures, including the aorta, vena cava, and renal and mesenteric vessels. Regardless, the risk of their malignant transformation justifies aggressive management [6]. We present a case of functional extra-adrenal sympathetic paraganglioma excision performed using general anaesthesia with optimal hemodynamic management during perioperative period.

CASE REPORT: A 40 year old man, from a rural place presented to the neurological OPD of our sister Institute with complaints of recurrent (5) episodes of cerebro vascular accidents (CVA) from the past 4 years. He was diagnosed to be hypertensive after the first attack and was started on Tab. Amlodipine $10 \mathrm{mg}$, tab. Citicoline $500 \mathrm{mg}$, tab. Clopidogrel $75 \mathrm{mg}$ OD. A routine ultrasound of the abdomen revealed a mass lesion below the left kidney. The patient was referred to our Institute for further management. On further taking the history, he had history of intermittent headache, fluctuating mood. There was no history or symptoms suggestive of diabetes mellitus. His family history did not suggest of any hereditary disorder. 
His physical examination showed that his height was $160 \mathrm{~cm}$, weight $50 \mathrm{~kg}$ and body mass index (BMI) was $19.53 \mathrm{~kg} / \mathrm{m}^{2}$; blood pressure measured $200 / 110 \mathrm{mmHg}$, basal heart rate of $100 /$ min. Neurological examination showed that he had right sided hemiparesis with minimal aphasia.

Pre-operative laboratory evaluation showed an $\mathrm{Hb}$ of $12 \mathrm{~g} / \mathrm{dl}$; haemogram, renal function tests, electrolytes, thyroid profile were within normal limits. Chest X-ray was normal. Electrocardiogram (ECG) showed features of left ventricular hypertrophy with no arrhythmias; his transthoracic echocardiogram had concentric LV hypertrophy, hypertensive heart disease, and ejection fraction of 65\%. $24 \mathrm{hr}$ urinary VMA test was $61 \mathrm{mg} /$ day. (Upper limit was $13.6 \mathrm{mg} /$ day). Ultrasound and computed tomography (CT) results showed a large, well-demarcated retroperitoneal tumor mass below the left kidney, measuring approximately $7 \times 6 \times 5 \mathrm{~cm}$, with both clear adrenals. Our patient was prepared for surgery with the addition of two more antihypertensive drugs, tab. Prazosin $2.5 \mathrm{mg}$ B.D. and tab. Metoprolol $50 \mathrm{mg}$ OD. He was scheduled for the laparoscopic excision of the tumor after adequate control of his hypertension.

On the day of the surgery, he received alprazolam $0.5 \mathrm{mg}$ orally 30 minutes before he was taken to the operating room. After establishing intravenous access and placing standard anesthesia monitors [non-invasive measurement of blood pressure (NIBP), ECG, SpO2 (pulse oximetry), and temperature], induction of anesthesia was made with propofol $100 \mathrm{mg}$, fentanyl $100 \mu \mathrm{g}$, lignocaine $80 \mathrm{mg}$ following vecuronium $8 \mathrm{mg}$ to facilitate endotracheal intubation. Our patient received an arterial line for invasive blood measurement and a central venous catheter in the right jugular vein for central venous pressure measurement. The anesthesia was maintained with isoflurane, in a mixture of $\mathrm{O}_{2}$ and air (in 40:60 ratios). Though the procedure was started laparoscopically, due to technical difficulty, it was converted to open surgical procedure. During the surgical excision of the tumor, severe and unexpected hemodynamic changes occurred. Minimal tumor manipulation was followed with severe hypertension measuring 205/110 $\mathrm{mmHg}$ and tachycardia up to 120 beats/minute. Inj. Labetalol was administered in incremental bolus of $5 \mathrm{mg}$ each to control the blood pressure. Inj. magnesium sulphate $\left(\mathrm{MgSO}_{4}\right) 2 \mathrm{~g}$ was administered by infusion. Due to a large intraoperative blood loss because of the tumor's extremely high vascularization our patient received high volume replacement in the form of crystalloids $(7500 \mathrm{ml})$; colloids $(2000 \mathrm{ml})$, under adequate central venous pressure monitoring and diuresis were maintained during the procedure. Immediately after excision of the tumor, our patient developed severe hypotension, due to the 'downregulation' of the receptors, with a lowest blood pressure measurement of $60 / 33 \mathrm{mmHg}$. The isoflurane was immediately discontinued. This condition was treated with additional large volume replacement with crystalloids, colloids, and vasopressors (norepinephrine up to $0.25 \mu \mathrm{g} / \mathrm{kg} / \mathrm{min}$ ) in order to achieve a mean arterial pressure (MAP) over $65 \mathrm{mmHg}$. After the procedure, our patient was promptly shifted to the intensive care unit (ICU) with the endotracheal tube in situ and connected to the ventilator. He was maintained with steroid supplementation with hydrocortisone $200 \mathrm{mg}$ intravenously, which was gradually tapered over the next few days. Analgesia was maintained with fentanyl infusion. His $\mathrm{Hb}$ had dropped to $6 \mathrm{gm} / \mathrm{dl}$, which was promptly corrected by administration of 4 units of packed red blood cells (PRBC), fresh frozen plasma (FFP). His vasopressor infusion was gradually tapered once his blood pressures were under control. Finally he was extubated on the second post operative day. He was transferred to the ward on the $5^{\text {th }}$ day and was discharged from hospital after 15 days. The final pathology report confirmed the presence of an extra adrenal sympathetic paraganglioma (EASP). 
DISCUSSION: Extra-adrenal paragangliomas have the ability, similar to pheochromocytomas, to be hormonally active. This onset of activity can result in sudden, life-threatening cardiovascular, neurological or metabolic crisis. A few patients (13 percent) may be asymptomatic in spite of high levels of circulating catecholamines due to receptor 'downregulation'. The asymptomatic features make it difficult for clinicians to detect the tumor at an early stage [7]. Detection is even more challenging for physicians working in rural areas as in this case who do not perform routine screening tests hypertension in the young.

A detailed history, physical examination, and a complete laboratory and cardiac evaluation are essential in preparation of the patient with pheochromocytoma/ paraganglioma for surgery. An accurate preoperative cardiovascular examination should be carried out, especially to detect the presence of a cardiomyopathy or coronary artery disease. As in this case, echocardiography can be helpful to delineate the degree of cardiac compromise, especially in patients with long-standing hypertension ${ }^{[8]}$.

Our patient's intraoperative hypertension was treated with labetalol in incremental doses intraoperatively. Additional hemodynamic control was obtained with slow infusion of MgSO4 to a total dose of $2 \mathrm{~g}$.We administered magnesium since it is widely reported in the anesthetic management of pheochromocytoma crisis as a vasodilator. The mechanism of magnesium's action lies in its ability to decrease catecholamine release. It is also a highly effective $\alpha$-adrenergic antagonist and anti-arrhythmic drug. Furthermore, magnesium appears to be predominantly an arteriolar dilator, reducing peripheral resistance but with minimal effect on venous return and therefore maintaining cardiac output. The ability of MgSO4 to control hemodynamic disturbances in the presence of extremely large catecholamine concentrations was demonstrated by the high levels of cardiovascular control obtained during surgery in our patient's case [9].

Furthermore, to ensure ideal preoperative preparation of patients with pheochromocytoma, very close communication between the endocrine, surgical, medical, cardiology, oncology, radiology, and anaesthesia teams is essential. Such teamwork should be directed to meet the three most essential goals: treat hypertension and tachyarrhythmias, restore the vascular volume, and treat any tumor or catecholamine excess-associated medical problems.

CONCLUSION: Functional paragangliomas carry high morbidity and mortality rates which can be potentially life threatening. Multiple pharmacotherapeutic interventions have been proposed to minimize intraoperative cardiovascular complications. It is important to have in mind the possible complications that can occur perioperatively while managing these patients. A thorough differential diagnosis is essential in order to plan the best treatment and therefore gain the best outcome for the patient. Patients, especially those with familial or extra adrenal tumors, should be followed-up indefinitely.

ACKNOWLEDGMENTS: Dr. Girish Nelvigi was the chief surgeon and provided the medical documents for the reported case.

We are grateful to our patient, who agreed to the reporting of this case report and provided all information needed.

\section{REFERENCES:}

1. Hayes WS, Davidson AJ, Grimley PM, Hartman DS: Extra adrenal retroperitoneal paraganglioma: clinical, pathologic, and CT findings. AJR Am J Roentgenol1990, 155:12471250. 
2. Kimura N, Capella C, De Krijger RR, Thompson LDR, Lam KY, Komminoth P, Tischler AS, Young WF: Extra-adrenal sympathetic paraganglioma: Superior and inferior paraaortic. In World Health Organization Classification of Tumours, Tumours of Endocrine Organs. Edited by DeLellis RA, Lloyd RV, Heitz PU, Eng C. Lyon, France: IARC Press; 2004a:164-165.

3. Soran PD, Akram S, Mihm F, Fleischmann D, Reitz B, van der Starre P: Unexpected findings during the anesthetic management of a patient with a cardiac paraganglioma. J Cardiothorac Vasc Anesth2008, 22:570-572.

4. Chiang KH, Liou JY, Shyu KG, Yeh CH, Wu CC, Chen TJ, Lo HM: Hypertension due to co-existing paraganglioma and unilateral adrenal cortical hyperplasia. J Formos Med Assoc2007, 106:1043-1047.

5. McClellan MW: New therapeutic and surgical approaches for sporadic and hereditary pheochromocytoma. Ann N Y Acad Sci2002, 970:41-53.

6. Myklejord DJ: Undiagnosed pheochromocytoma: the anesthesiologist nightmare. Clin Med Res2004, 2:59-62.

7. Subramaniam R, Pandit B, Sadhasivam S, Sridevi KB, Kaul HL: Retro peritoneoscopic excision of phaeochromocytoma - haemodynamic events, complications and outcome. Anaesth Intensive Care2000, 28:49-53.

8. Meune C, Bertherat J, Dousset B, Jude N, Bertagna X, Duboc D, Weber S Reduced myocardial contractility assessed by tissue Doppler echocardiography is associated with increased risk during adrenal surgery of patients with pheochromocytoma: report of a preliminary study. J Am Soc Echocardiogr 2006, 19:1466 -1470.

9. James FJ, Cronje L: Pheochromocytoma crisis: the use of magnesium sulfate. Anesth Analgesia2004,99:680-686

\section{AUTHORS:}

1. Pradeep M.S.

2. Lakshmish Yadav Y.S.

\section{PARTICULARS OF CONTRIBUTORS:}

1. Assistant Professor, Department of Anaesthesiology, Institute of Nephro Urology, Bangalore.

2. Assistant Professor, Department of Anaesthesiology, Institute of Nephro Urology, Bangalore.

\section{NAME ADRRESS EMAIL ID OF THE} CORRESPONDING AUTHOR:

Dr. Pradeep M.S., Assistant Professor in Anaesthesiology, Institute of Nephro Urology,

Victoria Hospital Campus,

Bangalore - 560002 .

Email-pradeepms@gmail.com

Date of Submission: 23/07/2013.

Date of Peer Review: 24/07/2013.

Date of Acceptance: 24/07/2013.

Date of Publishing: 26/07/2013 